\title{
Hypertrophic Cardiomyopathy: Updates Through the Lens of Sports Cardiology
}

Bradley S. Lander, $M D^{1}$

Dermot M. Phelan, MD PhD FESC FASE FACC ${ }^{2}$

Matthew W. Martinez, MD FACC 3,4 Elizabeth H. Dineen, DO FACC ${ }^{5, *}$

\author{
Address \\ ${ }^{1}$ Division of Cardiology, Columbia University Irving Medical Center, New York, NY, \\ 10032, USA \\ ${ }^{2}$ Sanger Heart \& Vascular Institute, Atrium Health, Charlotte, NC, 28203, USA \\ ${ }^{3}$ Department of Cardiovascular Medicine, Atlantic Health, Morristown Medical \\ Center, Morristown, NJ, 07960, USA \\ ${ }^{4}$ Sports Cardiology and Hypertrophic Cardiomyopathy, 111 S Madison Ave, Suite \\ 300, Morristown, NJ, 07960, USA \\ ${ }^{*}, 5$ Division of Cardiology, University of California Irvine, 333 City Blvd W, Suite \\ 400, Orange, CA, 92868, USA \\ Email: dineene@uci.edu
}

Published online: 25 May 2021

(C) The Author(s) 2021. This article is an open access publication

Dermot M. Phelan and Matthew W. Martinez are co-second authors

This article is part of Topical Collection on Sports Cardiology

Keywords Hypertrophic cardiomyopathy · Sports cardiology · Athlete - Exercise

\begin{abstract}
Purpose of review This review will summarize the distinction between hypertrophic cardiomyopathy ( $\mathrm{HCM}$ ) and exercise-induced cardiac remodeling (EICR), describe treatments of particular relevance to athletes with $\mathrm{HCM}$, and highlight the evolution of recommendations for exercise and competitive sport participation relevant to individuals with HCM. Recent findings Whereas prior guidelines have excluded individuals with HCM from more than mild-intensity exercise, recent data show that moderate-intensity exercise improves functional capacity and indices of cardiac function and continuation of competitive sports may not be associated with worse outcomes. Moreover, recent studies of athletes with implantable cardioverter defibrillators (ICDs) demonstrated a safer profile than previously understood. In this context, the updated American Heart Association/American College of Cardiology (AHA/ACC) and European Society of Cardiology (ESC) HCM guidelines have increased focus on shared decision-making and liberalized restrictions on exercise and sport participation among individuals with HCM.
\end{abstract}


Summary New data demonstrating the safety of exercise in individuals with HCM and in athletes with ICDs, in addition to a focus on shared decision-making, have led to the most updated guidelines easing restrictions on exercise and competitive athletics in this population. Further athlete-specific studies of HCM, especially in the context of emerging therapies such as mavacamten, are important to inform accurate risk stratification and eligibility recommendations.

\section{Introduction}

Hypertrophic cardiomyopathy (HCM) is a heterogenous and common inherited cardiac disorder defined by maximal left ventricular (LV) wall thickness $\geq 15 \mathrm{~mm}$ and disproportionate to loading conditions $[1,2 \bullet \bullet]$. The diagnosis can also be made with lesser degrees of $\mathrm{LV}$ hypertrophy $(\mathrm{LVH})$ in individuals with a positive family history or known genetic mutations $[1,2 \bullet \bullet]$. The combined prevalence of clinically expressed HCM and gene carriers has been recently estimated at 1:200 [3], though it is likely lower in highly trained athletes as structural and functional changes associated with the disorder select out many individuals from competitive athletics
[4]. Historically, sports activity has been associated with increased risk of sudden cardiac arrest (SCA) among individuals with underlying cardiovascular disease [5] and HCM was thought to be the most common cause of death in young athletes [6, 7]. As a result, prior guidelines restricted individuals with clinically apparent HCM from most competitive sports $[1,8-11]$. However, this paradigm has evolved. This review will highlight updated guidelines, with relevance to sports cardiology, for the diagnosis, risk stratification, treatment, and exercise recommendations for individuals with HCM.

\section{Diagnosis}

HCM is an autosomal-dominant condition caused by variants in sarcomeric protein genes defined by maximal end-diastolic LV wall thickness $\geq 15 \mathrm{~mm}$ in one or more LV myocardial segments as measured by echocardiography, cardiac magnetic resonance imaging (CMR), or computed tomography (CT), and disproportionate to hemodynamics or other pathological conditions such as long-standing hypertension or severe aortic stenosis $[1,2 \bullet \bullet]$. The diagnosis can also be made in individuals with lesser degrees of hypertrophy who have a positive family history or genetic mutations $[1,2 \bullet \bullet]$. Surveillance imaging is critical to monitor for the development or worsening of high-risk features and is particularly important for individuals who are genotype-positive but at first evaluation phenotype-negative.

Intense physical training is associated with cardiac remodeling. The details of one's remodeling depend on numerous factors including age, race, gender, and the type of sport and intensity [12-14]. Classically, power/static activities (such as weightlifting, American football, or shotput) are associated with increased 
afterload and peripheral vascular resistance with less pronounced effects on cardiac output. As such, they are characterized more by LVH and less chamber dilation. On the contrary, the consistent volume challenge associated with endurance sports (such as running) is more often associated with chamber dilation and augmented cardiac output [15]. However, the greatest degree of LVH occurs in those who also have the greatest increase in LV cavity size, the mixed sport athlete [14]. Approximately $2 \%$ of white athletes and up to $18 \%$ of black athletes have LVH with wall thickness in the "gray zone"; that is, less than the diagnostic threshold for HCM but above usual measurements, 13-14 mm in men and 12-13 mm in women [15-22]. Differentiating HCM from exerciseinduced cardiac remodeling (EICR) is challenging but has important therapeutic implications.

\section{Differentiating EICR and HCM}

\section{Electrocardiogram (ECG)}

Although 5-10\% of individuals with HCM have normal ECGs [23, 24], the majority demonstrate abnormalities including deep T-wave inversions (TWI), particularly in the inferolateral leads, ST segment depression or elevation, pathologic Q waves, and intraventricular conduction delay, which are not expected from athletic training $[23,25]$. When TWI are isolated to leads aVR, III, or V1, they may be considered a normal variant and in Black athletes may be considered normal when TWI in V1-V4 are preceded by domed ST segments [26]. However, in one study, approximately $5 \%$ of Black male athletes and 1.6\% of Black female athletes demonstrated pathologic TWI and nearly half of all athletes presenting with pathologic TWI were found to have identifiable cardiac disease, most commonly HCM [27]. The International Recommendations for Electrocardiographic Interpretation in Athletes were published in 2017 and serve as a valuable resource for clinicians who review the ECGs of athletes [25]. Isolated QRS voltage criteria for LVH are commonly seen in athletes; however, further evaluation is required when accompanied by two or more borderline ECG features such as atrial enlargement and axis deviation [25]. One study found that a $\mathrm{Q}+\mathrm{S}$ wave amplitude $>1.0 \mathrm{mV}$ in lead III was associated with septal thickness and more likely in individuals with HCM when compared with athletes; however, this study is not included in the ECG interpretation guidelines [28]. Abnormal ECG findings should prompt further investigation with imaging.

\section{Echocardiography}

Transthoracic echocardiography (TTE) is routinely used to evaluate suspected structural abnormalities. As opposed to athletes in which LVH is commonly symmetric and associated with LV chamber dilation, in HCM, the most common location for LVH is the basal anterior septum in continuity with the anterior free wall, though focal hypertrophy in only one or two LV segments is possible $[2 \bullet \bullet]$. Other features favoring HCM include myocardial crypts and abnormalities of the structure and function of the mitral valve and subvalvular apparatus including hypertrophied and apically displaced papillary muscles, 
anomalous insertion of the papillary muscle directly onto the anterior leaflet of the mitral valve, accessory chordal attachments, elongated mitral valve leaflets,

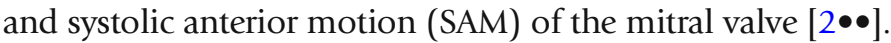

Several studies demonstrate that even in highly trained white athletes, $\mathrm{LVH}>$ $13 \mathrm{~mm}$ is extremely rare and, as such, measurements outside of this range should be investigated further $[4,16,29,30]$. However, the extent of LVH is greater in men, and in older, larger and Black athletes [13, 14, 31, 32].

In "gray zone" cases, athletes tend to have larger LV cavities than patients with HCM and an LV cavity size $<54 \mathrm{~mm}$ distinguished sedentary patients with HCM from athletes with physiologic remodeling in one small study [19] and $<$ $51 \mathrm{~mm}$ distinguished between athletes with $\mathrm{HCM}$ and physiologic remodeling in another study [23]. Moreover, diastolic function is most often normal in athletes with LVH as compared to patients with $\operatorname{HCM}[19,33,34]$. The caveat is that studies of diastolic function were not focused on strength-trained athletes, those most likely to have concentric LVH, and a recent study of American-style football players with concentric LVH demonstrated relative impairment of LV diastolic function which may be explained by resting hypertension in the population [35, 36]. Another study showed that athletes with HCM, as opposed to sedentary HCM patients, can have normal indices of diastolic function, thus diminishing its ability to distinguish certain cases in the "gray zone" [23].

Because up to one-third of individuals with HCM have latent left ventricular outflow tract (LVOT) obstruction, dynamic maneuvers, including exercise stress echocardiography, should be used to detect an exercise-induced LVOT gradient especially in the presence of exercise-induced symptoms [37].

\section{Cardiac magnetic resonance imaging}

Cardiac magnetic resonance (CMR) is an excellent diagnostic modality for proper assessment of chamber size, mass, and visualizing areas which may not be optimally visualized by TTE including the anterior free wall, posterior

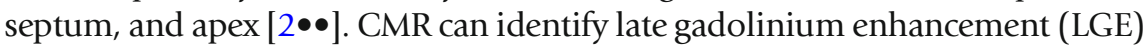
suggestive of fibrosis, which can be seen in $75 \%$ of people with HCM, most often in the segment of maximal wall thickness and at the anteroseptal and inferoseptal segments of insertion of the right ventricle [38]. Whereas LGE may be seen in long-term endurance athletes [39-41], its presence in young athletes has been less well described. LGE patterns suggestive of prior infarction or healed myocarditis are associated with increased cardiovascular risk, but less is known about the significance of a non-specific LGE pattern at the RV insertion points especially in asymptomatic individuals. Data on patterns of LGE among COVID-19 patients and comparable controls is still emerging and requires ongoing research. In one study of athletes with pathological TWI, initial TTE missed $46 \%$ of all diagnosed pathologic cases and CMR provided a diagnosis in $88 \%$ of all cardiomyopathies including $30 \%$ with "suspicious TTEs" [27]. Most of these were apical HCM which can be missed by TTE due to the limitations of echocardiographic image acquisition.

\section{Cardiopulmonary exercise testing}

Cardiopulmonary exercise testing (CPET) may be marginally helpful to differentiate HCM from EICR $[2 \bullet \bullet]$. One study compared athletic men with 
genetically proven HCM and mild LVH to elite athletes matched for age, size, and LV wall thickness and showed a greater peak oxygen uptake (pVO2), anaerobic threshold, and oxygen pulse among elite athletes [42]. A pVO2 > $50 \mathrm{ml} / \mathrm{kg} / \mathrm{min}$ or $>20 \%$ above the predicted $\mathrm{VO} 2$ max, anaerobic threshold $>$ $55 \%$ of predicted VO2 max, and an oxygen pulse $>30 \mathrm{ml} /$ beat differentiated athlete's heart from HCM [42]. Notably, the subjects with HCM were not elite athletes, and in our experience, some athletes with HCM can achieve metrics comparable to the elite athletes in this study.

\section{Detraining}

\section{Risk stratification}

Detraining involves stopping rigorous exercise to evaluate the effects on cardiac structure and function. It is used in certain cases in which the gray zone of hypertrophy remains undifferentiated despite a complete workup. Although there have been no studies in athletes with HCM detailing regression of hypertrophy, several small studies of athletes with eccentric hypertrophy $[43,44]$ and one small study of athletes with concentric hypertrophy have documented regression following periods of detraining [21]. This strategy should always be utilized with caution due to lack of normative data for the rate and completeness of expected LVH regression in healthy athletes, though atrophy of LV mass at a rate of $\sim 1 \% /$ week has been observed during strict bedrest in a non-athlete cohort [45]. This strategy may be challenging for elite athletes whose job or livelihood is dependent on maintaining peak physical performance.

Despite a normal life expectancy for most individuals with HCM [46] and data suggesting that most deaths are unrelated to HCM [47], the disease has been considered the most common and visible cause of SCA among young athletes in North America. This underscores the importance of distinguishing HCM

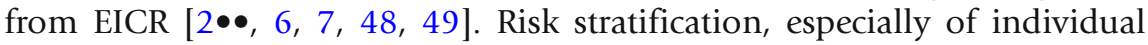
athletes, is challenging. The mechanism of death is thought to be from ventricular arrhythmias in the setting of myocardial disarray, interstitial collagen deposition, and scarring after myocyte death from microvascular dysfunction and ischemia, thus creating an unpredictable arrhythmogenic substrate [49]. A recent meta-analysis, however, suggested that a structurally normal heart was more common than HCM in young individuals with SCA [50]. This study suggested that, in total, there was no significant difference between HCM and structurally normal hearts among athletes, except for in Europe where structurally normal hearts were more common [50]. Repeated risk assessment for SCA every 1-2 years is critical for patients with HCM in order to identify high-risk patients who may benefit from an implantable cardioverter defibrillator (ICD).

A detailed personal and family history is paramount to risk stratification. Risk factors to consider include younger age at the time of evaluation, personal history of aborted cardiac arrest, unexplained syncope (particularly within 6 months as those occurring $>5$ years in the past have less significance), or a family history of sudden death, SCA, or sustained ventricular arrhythmias (VA) 
in $\geq 1$ first-degree relative $\leq 50$ years old or SCA in a first-degree relative with confirmed HCM (pre or post death diagnosis) at any age $[1,2,51,52,53 \bullet \bullet]$. Hypertension and epicardial coronary disease may also portend a worse prognosis in patients with HCM [54,55]. Moreover, as Drezner et al. recently discuss, Black athletes and male basketball, soccer, and American football players all appear to be at increased risk for SCA [56].

\section{Rhythm monitoring}

While the resting ECG has limited value, 24-48-h Holter or continuous 30-day ambulatory monitoring is more sensitive to detect non-sustained ventricular tachycardia (NSVT) and sustained VA and should include an exercise session [1, $2 \bullet \bullet, 51,52,53 \bullet \bullet, 54]$. Patients with HCM with prior SCA or sustained VA have the highest risk of subsequent events, about $10 \%$ per year [11].

Echocardiography is used to evaluate maximal wall thickness in the parasternal short and long axis planes, LVOT gradient (at rest and with Valsalva), and left atrial (LA) diameter. Exercise stress echocardiography can be used in individuals with exertional symptoms and resting SAM but absent or mild LVOT obstruction $[1,2 \bullet \bullet, 51,52,53 \bullet \bullet]$. Echocardiographic features which portend a worse prognosis include an LV ejection fraction $<50 \%$, apical aneurysm, and wall thickness $>30 \mathrm{~mm}[11,49,57]$.

\section{Cardiac magnetic resonance imaging}

Though LGE may be present in up to $75 \%$ of HCM patients, involvement of $\geq 15 \%$ of LV myocardium can identify individuals at higher risk of SCA and VA, even in the absence of other conventional risk factors [58]. Absence of LGE is associated with a lower risk of SCA and is more reassuring [58]. Furthermore, CMR can provide further characterization of maximal LV wall thickness, ejection fraction, and the presence of an

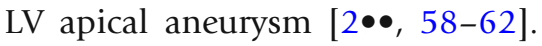

Exercise testing should be a part of routine evaluation. Abnormal blood pressure (BP) response (defined as $<20 \mathrm{mmHg}$ increase in systolic BP from baseline or exercise-induced hypotension) was thought to portend a worse prognosis but the evolution of SCA risk assessment has led to

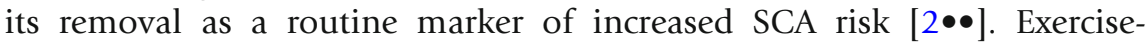
induced symptoms should lead to more conservative exercise/sporting

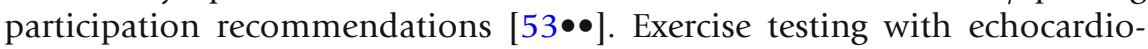
graphic guidance can aid in risk stratification. Maximal left ventricular outflow tract (LVOT) gradient to aid in calculating an estimated 5-year sudden death risk may be useful during shared decision-making for implantable ICD placement $[2 \bullet \bullet]$.

Genetic testing should be performed for familial screening, but because of significant genetic heterogeneity, does not inform risk of SCA or contribute to exercise recommendations $[53 \bullet \bullet, 57]$. 


\section{Treatment}

The ESC published a model to estimate individual 5-year risk of SCA to provide guidance on the need for prophylactic ICDs. The model incorporates seven variables: age, syncope, family history of SCA from HCM, maximal LV wall thickness, LA diameter, LVOT obstruction, and NSVT $[1,51]$. The guidelines delineate low $(<4 \%)$, moderate $(4-6 \%)$, and high risk $(\geq 6 \%)$. Notably, this was not created for athletes specifically and may not represent the true risk of SCA for athletes with HCM. It also does not account for LGE, reduced systolic function, or an LV apical aneurysm. Other studies have found the ESC-HCM model to have a low sensitivity for SCA and argue that the calculator, based on mathematical population models, leaves many individuals vulnerable [57, 63, 64]. Specifically, Maron et al. followed 2094 patients with HCM over 17 years and showed that the ESC risk score was less sensitive compared with an enhanced ACC/AHA risk factor strategy [65••]. Using this strategy, one of the following seven risk factors was considered sufficient evidence of increased SCA risk to justify prophylactic ICD implantation: (1) family history of SCA definitively or likely caused by HCM in $\geq 1$ first-degree or other close relative $\leq$ 50 years old, (2) LVH with wall thickness $>30 \mathrm{~mm}$, (3) unexplained syncope unlikely to be vasovagal within 5 years of evaluation, (4) NSVT, (5) extensive LGE (> 15\% LV mass), (6) LV ejection fraction $\leq 50 \%$, and (7) LV apical

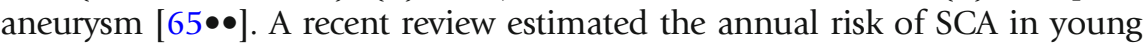
athletes with HCM to be between 0.1 and $6.6 \%$ per year [56]. Importantly, these data are extrapolated from small numbers in three studies of athletes who may not have had an established diagnosis of HCM and therefore potentially harbor significant risk factors. The risk of participation among low-risk athletes actively followed in sports cardiology clinics is likely lower. Maron et al. have demonstrated that SCA risk stratification has improved over time and the risk of SCA in those deemed "low risk" is extremely low $[65 \bullet \bullet, 66]$.

For patients with HCM, limitations to exercise tolerance are multifactorial and include LVOT obstruction [67]; diastolic dysfunction [68, 69]; abnormal hemodynamic response to exercise [70, 71]; predisposition to arrhythmias, including atrial fibrillation and NSVT [72-74]; mitral valve abnormalities [75]; and myocardial ischemia [76, 77]. Multimodal treatments in athletes include lifestyle adjustments, pharmacotherapy, and invasive options, and are primarily aimed at relief of symptoms associated with LVOT obstruction and prevention of SCA.

Proper hydration augments preload and is important for the two-thirds of HCM patients with obstruction; therefore, it is prudent to avoid dehydrating situations such as hot tubs, hot showers, and saunas, as well as exercising during concomitant illness. It is also recommended to avoid stimulants and the acute changes in preload and afterload that come with start-stop activities. However, regular moderate-intensity exercise is beneficial and should be encouraged in most patients with HCM as will be discussed later. For individuals with HCM 
who plan to participate in high-intensity activities after shared decision-making with an expert in the field, an emergency action plan is important and should include access to an automated external defibrillator (AED).

The most common and relevant issues that active individuals with HCM must manage include LVOT obstruction and associated symptoms, treated predominantly by negative inotropes, as well as the risk of SCA, addressed through the potential implantation of an ICD. Individuals with obstructive HCM should avoid pure vasodilators such as dihydropyridine calcium channel blockers, angiotensin-converting enzyme inhibitors, and angiotensin receptor blockers which decrease afterload and promote LVOT obstruction. Similarly, while lowdose diuretics may be necessary for individuals with congestive symptoms and those with non-obstructive HCM, high-dose diuretics, which may cause preload

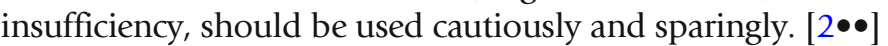

Beta blockade: First-line therapy includes non-vasodilating beta blockers titrated to a heart rate of approximately 60 beats per minute or relief of symptoms. Its efficacy is a result of negative inotropy, negative chronotropy, reduced LVOT gradients, increased systolic ejection time, and improved LV filling.

Considerations in active individuals: May produce unintended side effects such as fatigue, lethargy, or decreased cardiorespiratory fitness [78]. Use may be limited by baseline bradycardia in well-conditioned individuals. In general, they are well tolerated by both active and non-active individuals.

Non-dihydropyridine calcium channel antagonists: If beta blockers are ineffective, non-dihydropyridine calcium channel blockers, such as verapamil or diltiazem, can be used. These medications are negative inotropes and chronotropes and prolong diastolic filling time.

Considerations in active individuals: Caution in active individuals with baseline low blood pressure given the potential for vasodilation and hypotension. Peripheral edema is rare but may be more bothersome to this population than to sedentary individuals.

Disopyramide: Although less commonly used in active individuals, this is an option in individuals with incomplete response to beta blockers or calcium channel blockers and its benefit comes from strong negative inotropy.

Considerations in active individuals: Its anticholinergic properties, such as dry mouth and blurry vision, could affect performance. The need for hospital admission to monitor for potential arrhythmogenicity may disrupt training or competition schedules. [79] As a result of this potential side effect, guidelines

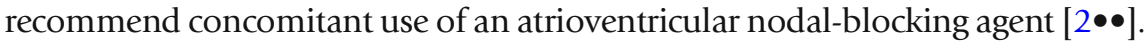

Septal reduction therapy with surgical myectomy is rarely considered in athletes with the possible exception of refractory exertional syncope in athletes with dynamic LVOT obstruction not attributable to other causes. Such cases are rare and not described in the guidelines.

Athletes may receive ICDs for secondary prevention following a life-threatening VA or for primary prevention according to disease-specific risk stratification. 
Based on limited data, prior consensus recommendations restricted athletes with ICDs to low-moderate dynamic and low static (1A) sports such as bowling or golf [80-83]. The concerns that led to these recommendations included the unknown efficacy of ICDs during exercise, the possibility of device malfunction, risk of injury to the athlete, or device from trauma and the potential for appropriate or inappropriate discharges.

The ICD Sports Registry was developed to follow athletes with ICDs who continued to compete in sports of greater intensity than the " $1 \mathrm{~A}$ " recommendation. Though shocks were common in 44 months of follow-up, there were no ICD failures, external resuscitations, injuries due to syncopal arrhythmias, or loss of control after shock [84]. More shocks were received during physical activity than rest, but there was no difference between competition or practice and other physical activity [84]. Importantly, though this registry includes athletes across numerous sports and cardiac conditions, no specific sub-analysis has been done of HCM patients. As a result of data from the ICD Sports Registry, the AHA/ACC updated guidelines note that participation in sports with an ICD is now a "IIb" recommendation, indicating it "may be considered". [85]

A sub-analysis of this registry performed to address appropriate ICD programming showed that inappropriate shocks were less likely with higher rate cut-offs for the first therapy zone (greater than 200 beats per minute) and with detection duration greater than "nominal" settings [86]. Individuals with both of those programming features were the least likely to receive inappropriate shocks. Importantly, there was no increase in syncope prior to shock in the athletes with these programming features. The presence of single or dual chamber devices and the number of therapy zones were not related to risk of shock Exercise testing after implantation may be helpful to determine the maximum sinus rate and to avoid T-wave oversensing [86].

Participants in the ICD Sports Registry had transvenous devices (except for a few epicardial systems). It is unknown whether subcutaneous-ICDs (S-ICD) are as effective or protected from lead damage to the same degree in athletes. In a recent review, Lampert described that athletes in sports requiring intense arm use, such as swimmers or rowers, may favor S-ICD due to the lower likelihood of "subclavian crush syndrome" in which the transvenous lead becomes compressed between the clavicle and first rib [87]. The review also noted that the position of the generator may drive the decision in specific contact sports; for example, the pre-pectoral placement of the generator in transvenous devices is better protected by standard padding in American football or ice hockey than an S-ICD which is located along the lateral, lower rib cage [87].

As was the case in prior guidelines, the most recent American HCM guidelines emphasize that ICDs should not be placed solely to allow for sports participation and do not serve as a substitute for disease-related recommendations that restrict participation $[2 \bullet \bullet]$.

\section{Exercise and competitive sport recommendations}

\section{Why is there concern about exercise and HCM?}

While regular physical activity is effective for primary and secondary prevention of numerous chronic diseases [88], there is concern that exercise and highintensity sports may cause maladaptive remodeling, VA and SCA among individuals with HCM [89]. The concern over risk is based on several proposed 
mechanisms (Fig. 1) [89-91]. Prior studies offer conflicting data regarding the true risk of SCA during exercise and competition and the proportion of which are due to HCM, with more recent studies in the general population and among athletes suggesting that structurally normal hearts are more common in SCA than previously thought $[5-7,48,50,92,93]$. Moreover, recent studies have shown that two-thirds of SCA in younger individuals with HCM died during routine activities, rest, or sleep [94], and was corroborated by a general population-based study in children and young adults [95]. Importantly, although a smaller proportion died during activity, the amount of time spent during the day in activity is less than the time at rest. However, a recent analysis by Maron et al. showed that 36\% of SCA in young competitive athletes with an autopsy-confirmed cardiovascular diagnosis were due to HCM and emphasizes the danger of trivializing the HCM-associated risk [96]. Based on similar data, guidelines historically have limited individuals with HCM to low-intensity, " $1 \mathrm{~A}$ " sports $[8,9,82,97]$. Perhaps as a result of messaging regarding the risks of exercise, surveys of individuals with HCM report that they are less active, more obese, and negatively affected emotionally compared to normal controls [98-100].

\section{What research has been done on HCM and exercise?}

Research in murine models with a mutant myosin heavy chain has shown a protective effect of early exercise on fibrosis and myofibrillar disarray when compared to exercise started later in life, suggesting that exercise may be beneficial especially early in the disease course. [101]

In humans, several studies have demonstrated the benefits of regular, moderate exercise in patients with HCM. The RESET-HCM trial showed that a 16week, moderate-intensity exercise program modestly increased peak $\mathrm{VO} 2$ compared with placebo [102] and Klempfner et al. showed that a supervised, gradual exercise program in symptomatic HCM patients improved functional capacity. [103] Neither study had serious events such as death or sustained VA

\section{Potential Risks of Exercise}

- Myocyte disarray and fibrosis: $\uparrow$ arrhythmogenicity

- Volume shifts: $\uparrow$ LVOT obstruction, syncope

- Abnormal intramural coronaries: $\uparrow$ ischemia

- Catecholamine surge: $\uparrow$ arrhythmogenicity

- Myocardial oxygen supply/ demand mismatch $\uparrow$

\section{Benefits of Exercise}

- Prevention and reversal of fibrosis and myocyte disarray*

- $\uparrow$ vagal tone: $\downarrow$ ventricular arrhythmias

- Peripheral adaptation: $\downarrow$ endothelial dysfunction in skeletal muscle vasculature and $\uparrow$ oxidative capacity

- Diastolic filling and stroke volume

- Traditional ASCVD risk factor reduction

Fig. 1. Exercise in hypertrophic cardiomyopathy. 
and though they were not powered for safety, the RESET-HCM trial had three patients withdrawn due to NSVT.

Dejgaard et al. demonstrated that vigorous activity was associated with larger LV volumes, favorable diastolic function, and no increase in VA among 132 individuals with $\mathrm{HCM}$, of whom 11 were competitive athletes. [104]

\section{What research has been done on HCM and exercise in athletes specifically?}

Whereas most data in HCM come from sedentary individuals, several studies have evaluated HCM in athletes. In an observational study, Sheikh et al. demonstrated that competitive athletes with HCM had lower mean LV wall thickness, larger LV end-diastolic diameter and volume, more normal indices of diastolic function, lower LVOT gradients, less mitral regurgitation, a lower incidence of SAM, and similar proportion with LGE when compared to nonathletes with HCM [23]. Like the Dejgaard study mentioned previously, it is unclear whether these are a result of training or indicators of less severe disease which allow for high-level athletic training. A recent study described an effective high-intensity exercise program that favorably affected LV end-diastolic filling, stroke volume, and fitness in healthy, sedentary, middle-aged individuals; this suggests that improvements in diastolic function and preventing cardiac stiffness attributed to aging may mediate favorable cardiac adaptations in athletes with HCM [89, 105].

More recently, Pelliccia et al. showed that among 35 mostly low-risk athletes with HCM, there was no difference in the incidence of symptoms or major events between athletes who stopped exercise and those who continued competitive sports [106•]. This group published a follow-up study of predominantly low risk, white athletes demonstrating no difference in symptoms or freedom from SCA/D between HCM-trained and detrained patients. They noted that similar results may not be seen in populations that are younger, racially diverse, or have more severe phenotypes [107].

Data from the ICD Sports Registry showed that among 440 athletes with ICDs, there were no deaths or external resuscitations during or after sports and the likelihood of receiving a shock was similar between competition and other physical activity among individuals with HCM [84].

More data is needed to appropriately comment on the efficacy and safety of high-intensity exercise in this population. The Dallas HIIT-HCM Pilot Study (High Intensity Exercise for Increasing Fitness in Patients with Hypertrophic Cardiomyopathy; NCT03335332) will strive to address this gap in knowledge [89].

\section{Exercise and sporting guidelines}

As more data emerge regarding the safety of exercise for individuals with HCM, American and European guidelines have evolved. Initial guidelines from the AHA/ACC in 2005 excluded athletes with "probable or unequivocal" HCM

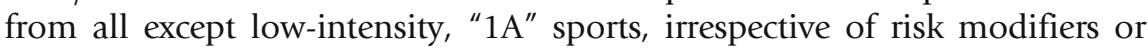
treatment [10]. European guidelines at the time forbade competitive sports in athletes with definite HCM but allowed athletes with a low-risk profile-no sudden death in relatives, no symptoms, mild LVH, normal blood pressure response to exercise, and no VA-to participate in low dynamic, low static, "1A" sports [8]. The American guidelines allowed 


\section{Shared decision-making}

genotype-positive-phenotype-negative individuals to participate in competitive sports, especially in the absence of cardiac symptoms or a family history of sudden death, whereas the European guidelines only allowed recreational, non-competitive sports for this population $[8,10]$.

The 2011 AHA/ACC HCM guidelines provided similar recommendations though also noted "it is reasonable for patients with HCM to participate in a range of recreation sporting activities" (Class IIa, Level of Evidence [LOE] C) [11]. The 2014 ESC-HCM guidelines still excluded athletes with HCM from competitive sports, though noted they "should maintain a healthy lifestyle" and that "advice on recreational activities should be tailored to symptoms and the risk of disease-related complications including SCA." [1].

Updated recommendations were published by the AHA/ACC in 2015 and 2020 and by the ESC in $2020[2 \bullet \bullet, 53 \bullet \bullet, 97]$. These recommendations are detailed in Table 1.

Individuals with HCM and their physicians must make decisions together regarding exercise, eligibility, SCA risk, and ICD implantation in the context of evolving data. As such, recent guidelines have shifted tone from generalized disqualifications to a nuanced focus on shared decision-making between pa-

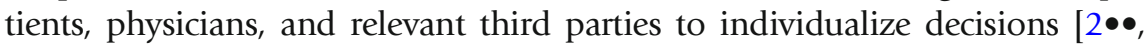
$53 \bullet \bullet$. The 2020 AHA/ACC HCM guidelines specifically encourage this to determine "participation in high-intensity recreational activities or moderateto high-intensity competitive sports activities," whereas prior recommendations categorically excluded them $[2 \bullet \bullet]$. Physicians should explain that risk varies based on age, race, specific sport, and phenotypic details and that existing risk calculators, such as the ESC-HCM SCA risk calculator, are derived from nonathletic cohorts and may not account for the specific stresses of exercise and high-intensity competition $[1,51,53 \bullet \bullet]$. Although recent guidelines allow for more liberalized participation, physicians should reiterate that SCA is possible even in the absence of all major risk factors [108]. Moreover, shared decisionmaking has limits; for example, patient autonomy is important but not without limitation especially considering that many young athletes may underestimate their individual vulnerability when faced with opportunities for fame and economic gain [56]. Other limits include the potential for disagreement among the athlete, team physicians and cardiologists, school or club and the delicate balance and legal ramifications regarding who has the final authority to permit or disqualify participation [56]. Ultimately, it is important that these decisions be made in concert with physicians experienced in both the cardiovascular care of athletes and patients with HCM and that all parties involved agree upon the final recommendation.

While most data come from cohorts of sedentary individuals with HCM, future studies of athletes with HCM will provide relevant data for future recommendations. Moreover, the ultimate introduction of newer medical therapies such as mavacamten into local formularies will present an 
Table 1. Evolution of AHA/ACC and ESC sport participation guidelines with HCM

\begin{tabular}{|c|c|c|c|}
\hline Guideline & $\begin{array}{l}\text { AHA/ACC Task Force } 3 \\
\text { (2015) }\end{array}$ & $\begin{array}{l}\text { ESC Sports Cardiology } \\
(2020)\end{array}$ & AHA/ACC HCM (2020) \\
\hline $\begin{array}{l}\text { Genotype } \\
(+) / \text { phenotype } \\
(-)\end{array}$ & $\begin{array}{l}\text { Participation in competitive } \\
\text { sports is reasonable if } \\
\text { asymptomatic and no family } \\
\text { history of HCM-related SCD } \\
\text { (IIa, C) }\end{array}$ & $\begin{array}{l}\text { Participation allowed in all } \\
\text { competitive sports (IIb, C) }\end{array}$ & $\begin{array}{l}\text { Participation in competitive } \\
\text { sports of any intensity is } \\
\text { reasonable (IIa, C-LD) }\end{array}$ \\
\hline \multirow{6}{*}{$\begin{array}{l}\text { Phenotype (+) } \\
\text { High-intensity }^{\#} \\
\text { competition/exercise } \\
\text { Low-moderate }^{\#} \\
\text { intensity } \\
\text { competition/exercise }\end{array}$} & \multirow{5}{*}{$\begin{array}{l}\text { Participation not } \\
\text { allowed-independent } \\
\text { of age/sex/magnitude of LV } \\
\text { hypertrophy/specific sarco- } \\
\text { mere } \\
\text { mutation, presence/absence } \\
\text { of LVOT } \\
\text { obstruction, absence of prior } \\
\text { symptoms, } \\
\text { presence of LGE, history of } \\
\text { septal } \\
\text { reduction therapy (III, C) }\end{array}$} & \multirow{5}{*}{$\begin{array}{l}\text { Any markers of increased } \\
\text { risk**: }^{* *} \text { participation not } \\
\text { recommended (II, C) } \\
\text { No markers of increased risk }{ }^{* *} \text { : } \\
\text { after } \\
\text { expert assessment, participation } \\
\text { may be considered } \\
\text { (except those where syncope } \\
\text { may be associated with harm } \\
\text { or death) (IIb, C) }\end{array}$} & \multirow{5}{*}{$\begin{array}{l}\text { High-intensity } \\
\text { recreation/moderate- } \\
\text { high-intensity competition: } \\
\text { may } \\
\text { be considered after } \\
\text { comprehensive } \\
\text { evaluation and shared } \\
\text { discussion, } \\
\text { repeated annually with an } \\
\text { expert } \\
\text { provider who conveys that } \\
\text { the } \\
\text { risk of sudden death and ICD } \\
\text { shocks may be increased, and } \\
\text { with the understanding that } \\
\text { eligibility } \\
\text { decisions for competitive } \\
\text { sports } \\
\text { often involve third parties } \\
\text { (IIb, C-LD) }\end{array}$} \\
\hline & & & \\
\hline & & & \\
\hline & & & \\
\hline & & & \\
\hline & $\begin{array}{l}\text { Low-intensity }(1 \mathrm{~A}) \text { sports } \\
\text { allowed-independent of } \\
\text { risk factors identified above } \\
(\mathrm{III}, \mathrm{C})\end{array}$ & $\begin{array}{l}\text { Any markers of increased } \\
\text { risk**: } \\
\text { low-moderate-intensity rec- } \\
\text { reation may be considered } \\
\text { following expert assessment } \\
\text { (IIb, C) }\end{array}$ & $\begin{array}{l}\text { Mild-moderate-intensity } \\
\text { recreation is beneficial (I, } \\
\text { B-NR) } \\
\text { Most patients with HCM: } \\
\text { low-intensity competition is rea- } \\
\text { sonable (IIa, C-EO) }\end{array}$ \\
\hline $\begin{array}{l}\text { Medications/ICDs } \\
\text { for sole purpose } \\
\text { of participation }\end{array}$ & $\begin{array}{l}\text { Medications (i.e.: BB): should } \\
\text { not be administered for sole } \\
\text { purpose of facilitating } \\
\text { participation in } \\
\text { high-intensity sports and } \\
\text { may interfere with maximum } \\
\text { physical performance (III, C) } \\
\text { Prophylactic ICDs for sole } \\
\text { purpose of participation: not } \\
\text { permitted. ICD indications for } \\
\text { athletes with HCM should not } \\
\text { differ from those in non-athletes } \\
\text { with HCM (III, B) }\end{array}$ & Not specifically addressed & $\begin{array}{l}\text { Prophylactic ICDs for sole } \\
\text { purpose of participation in } \\
\text { competitive athletics: should } \\
\text { not be performed (III, B-NR) }\end{array}$ \\
\hline $\begin{array}{l}\text { Evaluation and } \\
\text { follow-up }\end{array}$ & Not specifically addressed & $\begin{array}{l}\text { Annual follow-up for individuals } \\
\text { who exercise on a regular } \\
\text { basis }(I, C) \text { and considered }\end{array}$ & $\begin{array}{l}\text { Comprehensive evaluation and } \\
\text { shared discussion of } \\
\text { potential risks of sports }\end{array}$ \\
\hline
\end{tabular}


Table 1. (Continued)

Guideline

AHA/ACC Task Force 3 (2015)

\section{ESC Sports Cardiology (2020)}

for genotype (+)/phenotype

$(-)$ individuals for phenotypic review and risk stratification

Six-month follow-up for adolescents and young adults who are more vulnerable to

exercise-related SCD (IIa C)

\section{AHA/ACC HCM (2020)}

participation by an expert provider is recommended on an annual basis (I, C-EO)

AHA, American Heart Association; ACC, American College of Cardiology; ESC, European Society of Cardiology; HCM, hypertrophic cardiomyopathy; $S C D$, sudden cardiac death; $L D$, limited data; $E O$, expert opinion; $L V$, left ventricle; $L V O T$, left ventricular outflow tract; $L G E$, late gadolinium enhancement; $I C D$, implantable cardioverter defibrillator; $N R$, non-randomized; $B B$, beta blocker

${ }^{*}$ Guideline recommendations in parentheses (Class, Level of Evidence)

** Markers of increased risk: (1) Cardiac symptoms or history of cardiac arrest or unexplained syncope; (2) moderate ESC risk score ( $\geq 4 \%$ ) at 5 years; (3) LVOT gradient at rest $>30 \mathrm{mmHg}$; (4) abnormal blood pressure response to exercise; (5) exercise-induced arrhythmias

\#Examples of intensity: Low: bowling, golf; moderate: figure skating, rugby, running; high: kayaking, cycling, triathlon. See Levine et al. Task Force 1 Classification of Sport. JACC 2015 Dec 1;66(21):2350-2355 for full figure

\section{Conclusion}

opportunity to evaluate the degree to which regression of hypertrophy changes the risk of SCA and other cardiovascular outcomes. Mavacamten inhibits cardiac myosin ATPase which reduces actin-myosin cross-bridge formation and reduces contractility. As a result, the EXPLORER-HCM trial showed it reduces LVOT gradients, improves symptoms, NYHA class, and peak VO2 in patients with obstructive HCM compared to placebo at 30 weeks $[109,110]$. Notably, this trial was not done in athletes specifically. The mean age of participants was 58.5 years, likely much older than most athletes and $>90 \%$ in the mavacamten arm were white, which is not representative of athletes. It is unknown whether or how reverse remodeling will affect SCA risk.

Building upon existing ICD data to further characterize outcomes in HCM-specific populations will help inform treatment in this evolving area of debate. Finally, as the AHA/ACC and ESC have liberalized exclusions for moderate- to high-intensity exercise, further characterizing the safety of these activities for individuals with HCM will inform more data-driven recommendations.

Differentiating HCM and EICR is challenging and often requires a nuanced interpretation of several diagnostic tools. Individuals with HCM may have an increased risk for cardiac arrest and identification of established risk factors is paramount for patient discussions and decisions. Correctly distinguishing pathology from expected remodeling has implications for activity recommendations and treatment. Whereas previous guidelines from the AHA/ACC and ESC have excluded individuals with HCM from moderate- to high-intensity sports and competition, recent data and a focus on shared decision-making have led to the most 
recent guidelines offering and individualized approach for this population as a whole and among individuals with ICDs. Further studies of athletes with HCM and ICDs as well as the risk reduction profile of emerging therapies such as mavacamten will meaningfully improve the ability to risk stratify and appropriately manage athletes with HCM.

\section{Compliance with Ethical Standards}

\section{Conflict of Interest}

Bradley S. Lander, Dermot M. Phelan, Matthew W. Martinez and Elizabeth H. Dineen declare that they have no conflict of interest.

\section{Human and Animal Rights and Informed Consent}

This article does not contain any studies with human or animal subjects performed by any of the authors.

\section{Open Access}

This article is licensed under a Creative Commons Attribution 4.0 International License, which permits use, sharing, adaptation, distribution and reproduction in any medium or format, as long as you give appropriate credit to the original author(s) and the source, provide a link to the Creative Commons licence, and indicate if changes were made. The images or other third party material in this article are included in the article's Creative Commons licence, unless indicated otherwise in a credit line to the material. If material is not included in the article's Creative Commons licence and your intended use is not permitted by statutory regulation or exceeds the permitted use, you will need to obtain permission directly from the copyright holder. To view a copy of this licence, visit http://creativecommons.org/licenses/by/4.0/.

\section{References and Recommended Reading}

Papers of particular interest, published recently, have been highlighted as:

- Of importance

$\bullet$ Of major importance

1. Elliott PM, Anastasakis A, Borger MA, Borggrefe M, Cecchi F, Charron P, et al. 2014 ESC Guidelines on diagnosis and management of hypertrophic cardiomyopathy: the Task Force for the Diagnosis and Management of Hypertrophic Cardiomyopathy of the European Society of Cardiology (ESC). Eur Heart J. 2014;35(39):2733-79.

2.• Ommen SR, Mital S, Burke MA, Day SM, Deswal A, Elliott $P$, et al. 2020 AHA/ACC Guideline for the diagnosis and treatment of patients with hypertrophic cardiomyopathy: a report of the American College of Cardiology/American Heart Association Joint
Committee on Clinical Practice Guidelines. J Am Coll Cardiol. 2020;76:e159-240

These American guidelines were updated in 2020 and review the definition, pathophysiology, diagnosis, risk assessment, and shared decision-making recommendations of the AHA/ACC.

3. Semsarian C, Ingles J, Maron MS, Maron BJ. New perspectives on the prevalence of hypertrophic cardiomyopathy. J Am Coll Cardiol. 2015;65(12):1249-54.

4. Basavarajaiah S, Wilson M, Whyte G, Shah A, McKenna W, Sharma S. Prevalence of hypertrophic cardiomyopathy in highly trained athletes: relevance to pre- 
participation screening. J Am Coll Cardiol. 2008;51(10):1033-9.

5. Corrado D, Basso C, Rizzoli G, Schiavon M, Thiene G. Does sports activity enhance the risk of sudden death in adolescents and young adults? J Am Coll Cardiol. 2003;42(11):1959-63.

6. Maron BJ, Shirani J, Poliac LC, Mathenge R, Roberts $\mathrm{WC}$, Mueller FO. Sudden death in young competitive athletes. Clinical, demographic, and pathological profiles. JAMA. 1996;276(3):199-204.

7. Maron BJ. Sudden death in young athletes. N Engl J Med. 2003;349(11):1064-75.

8. Pelliccia A, Fagard R, Bjørnstad HH, Anastassakis A, Arbustini E, Assanelli D, et al. Recommendations for competitive sports participation in athletes with cardiovascular disease: a consensus document from the Study Group of Sports Cardiology of the Working Group of Cardiac Rehabilitation and Exercise Physiology and the Working Group of M. Eur Heart J. 2005;26(14):1422-45.

9. Maron BJ, Chaitman BR, Ackerman MJ, Bayés de Luna A, Corrado D, Crosson JE, et al. Recommendations for physical activity and recreational sports participation for young patients with genetic cardiovascular diseases. Circulation. 2004;109(22):2807-2816.

10. Maron BJ, Ackerman MJ, Nishimura RA, Pyeritz RE, Towbin JA, Udelson JE. Task Force 4: HCM and other cardiomyopathies, mitral valve prolapse, myocarditis, and Marfan syndrome. J Am Coll Cardiol. 2005;45(8):1340-5.

11. Gersh BJ, Maron BJ, Bonow RO, Dearani JA, Fifer MA, Link MS, et al. 2011 ACCF/AHA guideline for the diagnosis and treatment of hypertrophic cardiomyopathy: executive summary: a report of the American College of Cardiology Foundation/American Heart Association Task Force on Practice Guidelines. Circulation. 2011;124(24):2761-96.

12. Morganroth J, Maron BJ, Henry WL, Epstein SE. Comparative left ventricular dimensions in trained athletes. Ann Intern Med. 1975;82(4):521-4.

13. Rawlins J, Carre F, Kervio G, Papadakis M, Chandra N, Edwards $\mathrm{C}$, et al. Ethnic differences in physiological cardiac adaptation to intense physical exercise in highly trained female athletes. Circulation, 1085. 2010;9, 121(9):1078 Available from: https://www.ncbi.nlm. nih.gov/pubmed/20176985.

14. Sharma S. Athlete's heart-effect of age, sex, ethnicity and sporting discipline. Exp Physiol. 2003;88(5):6659.

15. Wasfy MM, Weiner RB. Differentiating the athlete's heart from hypertrophic cardiomyopathy. Curr Opin Cardiol [Internet]. 2015;30(5):500-5 Available from: https://www.ncbi.nlm.nih.gov/pubmed/26196658.

16. Pelliccia A, Maron BJ, Spataro A, Proschan MA, Spirito $P$. The upper limit of physiologic cardiac hypertrophy in highly trained elite athletes. $\mathrm{N}$ Engl J Med [Internet]. 1991;324(5):295-301 Available from: https://www. ncbi.nlm.nih.gov/pubmed/1824720.
17. Maron BJ, Pelliccia A. The heart of trained athletes: cardiac remodeling and the risks of sports, including sudden death. Circulation [Internet].

2006;114(15):1633-44 Available from: https://www. ncbi.nlm.nih.gov/pubmed/17030703.

18. Brosnan M, Rakhit D. Differentiating athlete's heart from cardiomyopathies - the left side. Hear Lung Circ. 2018;27:1052-62.

19. Caselli S, Maron MS, Urbano-Moral JA, Pandian NG, Maron BJ, Pelliccia A. Differentiating left ventricular hypertrophy in athletes from that in patients with hypertrophic cardiomyopathy. Am J Cardiol [Internet]. 2014;114(9):1383-9 Available from: https://www. ncbi.nlm.nih.gov/pubmed/25217454.

20. Maron BJ, Pelliccia A, Spirito P. Cardiac disease in young trained athletes. Insights into methods for distinguishing athlete's heart from structural heart disease, with particular emphasis on hypertrophic cardiomyopathy. Circulation [Internet]. 1995;91(5):1596-601 Available from: https://www. ncbi.nlm.nih.gov/pubmed/7867202.

21. Weiner RB, Wang F, Berkstresser B, Kim J, Wang TJ, Lewis GD, et al. Regression of "gray zone" exerciseinduced concentric left ventricular hypertrophy during prescribed detraining. J Am Coll Cardiol [Internet]. 2012;59(22):1992-4 Available from: https://www. ncbi.nlm.nih.gov/pubmed/22624842.

22. Basavarajaiah S, Boraita A, Whyte G, Wilson M, Carby $\mathrm{L}$, Shah A, et al. Ethnic differences in left ventricular remodeling in highly-trained athletes relevance to differentiating physiologic left ventricular hypertrophy from hypertrophic cardiomyopathy. J Am Coll Cardiol [Internet]. 2008;51(23):2256-62 Available from: https://www.ncbi.nlm.nih.gov/pubmed/18534273.

23. Sheikh N, Papadakis M, Schnell F, Panoulas V, Malhotra A, Wilson M, et al. Clinical profile of athletes with hypertrophic cardiomyopathy. Circ Cardiovasc Imaging [Internet]. 2015;8(7):e003454-4 Available from: https://www.ncbi.nlm.nih.gov/pubmed/ 26198026.

24. Rowin EJ, Maron BJ, Appelbaum E, Link MS, Gibson $\mathrm{CM}$, Lesser JR, et al. Significance of false negative electrocardiograms in preparticipation screening of athletes for hypertrophic cardiomyopathy. Am J Cardiol. 2012;110(7):1027-32.

25. Sharma S, Drezner JA, Baggish A, Papadakis M, Wilson MG, Prutkin JM, et al. International recommendations for electrocardiographic interpretation in athletes. J Am Coll Cardiol [Internet]. 2017;69(8):1057-75 Available from: https://www.ncbi.nlm.nih.gov/pubmed/ 28231933.

26. Papadakis M, Carre F, Kervio G, Rawlins J, Panoulas VF, Chandra N, et al. The prevalence, distribution, and clinical outcomes of electrocardiographic repolarization patterns in male athletes of African/AfroCaribbean origin. Eur Heart J. 2011;32(18):2304-13. 27. Schnell F, Riding N, O'Hanlon R, Axel Lentz P, Donal E, Kervio G, et al. Recognition and significance of 
pathological T-wave inversions in athletes. Circulation. 2015;131(2):165-73.

28. Chen AS, Bent RE, Wheeler M, Knowles JW, Haddad F, Froelicher V, et al. Large Q and S waves in lead III on the electrocardiogram distinguish patients with hypertrophic cardiomyopathy from athletes. Heart.

2018;104(22):1871-7.

29. Sharma S, Maron BJ, Whyte G, Firoozi S, Elliott PM, McKenna WJ. Physiologic limits of left ventricular hypertrophy in elite junior athletes: relevance to differential diagnosis of athlete's heart and hypertrophic cardiomyopathy. J Am Coll Cardiol. 2002;40(8):1431-6.

30. Weiner RB, Wang F, Hutter AMJ, Wood MJ, Berkstresser B, McClanahan C, et al. The feasibility, diagnostic yield, and learning curve of portable echocardiography for out-of-hospital cardiovascular disease screening. J Am Soc Echocardiogr Off Publ Am Soc Echocardiogr. 2012;25(5):568-75.

31. Pelliccia A, Maron BJ, Culasso F, Spataro A, Caselli G. Athlete's heart in women. Echocardiographic characterization of highly trained elite female athletes. JAMA. 1996;276(3):211-5.

32. Pluim BM, Zwinderman AH, van der Laarse A, van der Wall EE. The athlete's heart. A meta-analysis of cardiac structure and function. Circulation [Internet]. 2000;101(3):336-44 Available from: https://www. ncbi.nlm.nih.gov/pubmed/10645932.

33. Lewis JF, Spirito P, Pelliccia A, Maron BJ. Usefulness of Doppler echocardiographic assessment of diastolic filling in distinguishing "athlete's heart" from hypertrophic cardiomyopathy. Br Heart J. 1992;68(3):296300.

34. Vinereanu D, Florescu N, Sculthorpe N, Tweddel AC, Stephens MR, Fraser AG. Differentiation between pathologic and physiologic left ventricular hypertrophy by tissue Doppler assessment of long-axis function in patients with hypertrophic cardiomyopathy or systemic hypertension and in athletes. Am J Cardiol. 2001;88(1):53-8.

35. Baggish AL, Wang F, Weiner RB, Elinoff JM, Tournoux $\mathrm{F}$, Boland $\mathrm{A}$, et al. Training-specific changes in cardiac structure and function: a prospective and longitudinal assessment of competitive athletes. J Appl Physiol. 2008;104(4):1121-8.

36. Weiner RB, Wang F, Isaacs SK, Malhotra R, Berkstresser $\mathrm{B}, \mathrm{Kim} \mathrm{JH}$, et al. Blood pressure and left ventricular hypertrophy during American-style football participation. Circulation. 2013;128(5):524-31.

37. Rowin EJ, Maron BJ, Olivotto I, Maron MS. Role of exercise testing in hypertrophic cardiomyopathy. JACC Cardiovasc Imaging. 2017;10(11):1374-86.

38. Rudolph A, Abdel-Aty H, Bohl S, Boyé P, Zagrosek A, Dietz R, et al. Noninvasive detection of fibrosis applying contrast-enhanced cardiac magnetic resonance in different forms of left ventricular hypertrophy relation to remodeling. J Am Coll Cardiol. 2009;53(3):284-91.

39. La Gerche A, Burns AT, Mooney DJ, Inder WJ, Taylor AJ, Bogaert J, et al. Exercise-induced right ventricular dysfunction and structural remodelling in endurance athletes. Eur Heart J. 2012;33(8):998-1006 Available from: https://www.ncbi.nlm.nih.gov/pubmed/ 22160404.

40. Wilson M, O'Hanlon R, Prasad S, Deighan A, Macmillan $\mathrm{P}$, Oxborough D, et al. Diverse patterns of myocardial fibrosis in lifelong, veteran endurance athletes. J Appl Physiol. 2011;110(6):1622-6.

41. Domenech-Ximenos B, Sanz-de la Garza M, PratGonzález S, Sepúlveda-Martínez A, Crispi F, DuranFernandez K, et al. Prevalence and pattern of cardiovascular magnetic resonance late gadolinium enhancement in highly trained endurance athletes. J Cardiovasc Magn Reson Off J Soc Cardiovasc Magn Reson. 2020;22(1):62.

42. Sharma S, Elliott PM, Whyte G, Mahon N, Virdee MS, Mist $B$, et al. Utility of metabolic exercise testing in distinguishing hypertrophic cardiomyopathy from physiologic left ventricular hypertrophy in athletes. J Am Coll Cardiol. 2000;36(3):864-70.

43. Pelliccia A, Maron BJ, De Luca R, Di Paolo FM, Spataro A, Culasso F. Remodeling of left ventricular hypertrophy in elite athletes after long-term deconditioning. Circulation. 2002;105(8):944-9 Available from: https://www.ncbi.nlm.nih.gov/pubmed/11864923.

44. Maron BJ, Pelliccia A, Spataro A, Granata M. Reduction in left ventricular wall thickness after deconditioning in highly trained Olympic athletes. Br Heart J. 1993;69(2):125-8.

45. Perhonen MA, Franco F, Lane LD, Buckey JC, Blomqvist CG, Zerwekh JE, et al. Cardiac atrophy after bed rest and spaceflight. J Appl Physiol. 2001;91(2):645-53

46. Cannan CR, Reeder GS, Bailey KR, Melton LJ 3rd, Gersh BJ. Natural history of hypertrophic cardiomyopathy. A population-based study, 1976 through 1990. Circulation. 1995;92(9):2488-95.

47. Maron BJ, Rowin EJ, Casey SA, Garberich RF, Maron MS. What do patients with hypertrophic cardiomyopathy die from? Am J Cardiol. 2016;117(3):434-5.

48. Maron BJ, Doerer JJ, Haas TS, Tierney DM, Mueller FO. Sudden deaths in young competitive athletes: analysis of 1866 deaths in the United States, 1980-2006. Circulation. 2009;119(8):1085-92 Available from: https://www.ncbi.nlm.nih.gov/pubmed/19221222.

49. Maron BJ. Clinical course and management of hypertrophic cardiomyopathy. N Engl J Med. 2018;379(7):655-68.

50. Ullal AJ, Abdelfattah RS, Ashley EA, Froelicher VF. Hypertrophic cardiomyopathy as a cause of sudden cardiac death in the young: a meta-analysis. Am J Med. 2016;129(5):486-496.e2.

51. O'Mahony C, Jichi F, Ommen SR, Christiaans I, Arbustini E, Garcia-Pavia P, et al. International external validation study of the 2014 European Society of Cardiology Guidelines on Sudden Cardiac Death Prevention in Hypertrophic Cardiomyopathy (EVIDENCEHCM). Circulation. 2018;137(10):1015-23. 
52. Pelliccia A, Solberg EE, Papadakis M, Adami PE, Biffi A, Caselli $S$, et al. Recommendations for participation in competitive and leisure time sport in athletes with cardiomyopathies, myocarditis, and pericarditis: position statement of the Sport Cardiology Section of the European Association of Preventive Cardiology (EAPC). Eur Heart J. 2019;40(1):19-33.

53.• Pelliccia A, Sharma S, Gati S, Bäck M, Börjesson M, Caselli S, et al. 2020 ESC Guidelines on sports cardiology and exercise in patients with cardiovascular disease. Eur Heart J. 2021;42(1):17-96

These European guidelines were updated in 2020 and cover HCM as well as other cardiovascular conditions as they relate to athletes and exercise.

54. Sheikh N, Papadakis M, Panoulas VF, Prakash K, Millar L, Adami P, et al. Comparison of hypertrophic cardiomyopathy in Afro-Caribbean versus white patients in the UK. Heart. 2016;102(22):1797-804.

55. Sorajja P, Ommen SR, Nishimura RA, Gersh BJ, Berger $\mathrm{PB}$, Tajik AJ. Adverse prognosis of patients with hypertrophic cardiomyopathy who have epicardial coronary artery disease. Circulation. 2003;108(19):2342-8.

56. Drezner JA, Malhotra A, Prutkin JM, Papadakis M, Harmon KG, Asif IM, et al. Return to play with hypertrophic cardiomyopathy: are we moving too fast? A critical review. Br J Sports Med. 2021.

57. Maron BJ, Maron MS. Contemporary strategies for risk stratification and prevention of sudden death with the implantable defibrillator in hypertrophic cardiomyopathy. Heart Rhythm. 2016;13(5):1155-65.

58. Chan RH, Maron BJ, Olivotto I, Pencina MJ, Assenza GE, Haas T, et al. Prognostic value of quantitative contrast-enhanced cardiovascular magnetic resonance for the evaluation of sudden death risk in patients with hypertrophic cardiomyopathy. Circulation.

2014;130(6):484-95.

59. Ismail TF, Jabbour A, Gulati A, Mallorie A, Raza S, Cowling TE, et al. Role of late gadolinium enhancement cardiovascular magnetic resonance in the risk stratification of hypertrophic cardiomyopathy. Heart. 2014;100(23):1851-8.

60. Weng Z, Yao J, Chan RH, He J, Yang X, Zhou Y, et al. Prognostic value of LGE-CMR in HCM: a meta-analysis. JACC Cardiovasc Imaging. 2016;9(12):1392-402.

61. Mentias A, Raeisi-Giglou P, Smedira NG, Feng K, Sato $\mathrm{K}$, Wazni $\mathrm{O}$, et al. Late gadolinium enhancement in patients with hypertrophic cardiomyopathy and preserved systolic function. J Am Coll Cardiol. 2018;72(8):857-70.

62. Maron MS, Finley JJ, Bos JM, Hauser TH, Manning WJ, Haas TS, et al. Prevalence, clinical significance, and natural history of left ventricular apical aneurysms in hypertrophic cardiomyopathy. Circulation. 2008;118(15):1541-9.

63. Maron BJ, Casey SA, Chan RH, Garberich RF, Rowin EJ, Maron MS. Independent assessment of the European Society of Cardiology Sudden Death Risk Model for Hypertrophic Cardiomyopathy. Am J Cardiol. 2015;116(5):757-64.
64. Leong KMW, Chow J-J, Ng FS, Falaschetti E, Qureshi N, Koa-Wing M, et al. Comparison of the prognostic usefulness of the European Society of Cardiology and American Heart Association/American College of Cardiology Foundation Risk Stratification Systems for Patients With Hypertrophic Cardiomyopathy. Am J Cardiol. 2018;121(3):349-55.

65.• Maron MS, Rowin EJ, Wessler BS, Mooney PJ, Fatima A, Patel P, et al. Enhanced American College of Cardiology/American Heart Association strategy for prevention of sudden cardiac death in high-risk patients with hypertrophic cardiomyopathy. JAMA Cardiol [Internet]. 2019;4(7):644-57. https://doi.org/10.1001/ jamacardio.2019.1391

Describes a systematic enhanced ACC/AHA guideline and practice-based risk factor approach that prospectively predicted SCA with high sensitivity.

66. Maron BJ, Rowin EJ, Casey SA, Lesser JR, Garberich RF, McGriff DM, et al. Hypertrophic cardiomyopathy in children, adolescents, and young adults associated with low cardiovascular mortality with contemporary management strategies. Circulation. 2016;133(1):6273.

67. Arshad W, Duncan AM, Francis DP, O'Sullivan CA, Gibson DG, Henein MY. Systole-diastole mismatch in hypertrophic cardiomyopathy is caused by stress induced left ventricular outflow tract obstruction. Am Heart J. 2004;148(5):903-9.

68. Matsumura Y, Elliott PM, Virdee MS, Sorajja P, Doi Y, McKenna WJ. Left ventricular diastolic function assessed using Doppler tissue imaging in patients with hypertrophic cardiomyopathy: relation to symptoms and exercise capacity. Heart. 2002;87(3):247-51.

69. Mizukoshi K, Suzuki K, Yoneyama K, Kamijima R, Kou $\mathrm{S}$, Takai $\mathrm{M}$, et al. Early diastolic function during exertion influences exercise intolerance in patients with hypertrophic cardiomyopathy. J Echocardiogr. 2013;11(1):9-17.

70. Ciampi Q, Betocchi S, Lombardi R, Manganelli F, Storto G, Losi MA, et al. Hemodynamic determinants of exercise-induced abnormal blood pressure response in hypertrophic cardiomyopathy. J Am Coll Cardiol. 2002;40(2):278-84.

71. Efthimiadis GK, Giannakoulas G, Parcharidou DG, Pagourelias ED, Kouidi EJ, Spanos G, et al. Chronotropic incompetence and its relation to exercise intolerance in hypertrophic cardiomyopathy. Int J Cardiol. 2011;153(2):179-84.

72. Olivotto I, Cecchi F, Casey SA, Dolara A, Traverse JH, Maron BJ. Impact of atrial fibrillation on the clinical course of hypertrophic cardiomyopathy. Circulation. 2001; 104(21):2517-24.

73. Azarbal F, Singh M, Finocchiaro G, Le V-V, Schnittger I, Wang $\mathrm{P}$, et al. Exercise capacity and paroxysmal atrial fibrillation in patients with hypertrophic cardiomyopathy. Heart. 2014;100(8):624-30.

74. Gimeno JR, Tomé-Esteban M, Lofiego C, Hurtado J, Pantazis A, Mist B, et al. Exercise-induced ventricular arrhythmias and risk of sudden cardiac death in 
patients with hypertrophic cardiomyopathy. Eur Heart J. 2009;30(21):2599-605.

75. Henein M, Arvidsson S, Pilebro B, Backman C, Mörner $\mathrm{S}$, Lindqvist $\mathrm{P}$. Long mitral valve leaflets determine left ventricular outflow tract obstruction during exercise in hypertrophic cardiomyopathy. Int J Cardiol.

2016;212:47-53.

76. Raphael CE, Cooper R, Parker KH, Collinson J, Vassiliou V, Pennell DJ, et al. Mechanisms of myocardial ischemia in hypertrophic cardiomyopathy: insights from wave intensity analysis and magnetic resonance. J Am Coll Cardiol. 2016;68(15):1651-60.

77. Basu J, Malhotra A, Papadakis M. Exercise and hypertrophic cardiomyopathy: two incompatible entities? Clin Cardiol. 2020;43(8):889-96.

78. Nielen JTH, de Vries F, van der Velde JHPM, Savelberg HHCM, Schaper NC, Dagnelie PC, et al. The association between $\beta$-blocker use and cardiorespiratory fitness: the Maastricht study. J Cardiovasc Pharmacol Ther. 2019;24(1):37-45.

79. Verlinden NJ, Coons JC. Disopyramide for hypertrophic cardiomyopathy: a pragmatic reappraisal of an old drug. Pharmacotherapy. 2015;35(12):1164-72.

80. Maron BJ, Zipes DP. Introduction: eligibility recommendations for competitive athletes with cardiovascular abnormalities-general considerations. J Am Coll Cardiol. 2005;45(8):1318-21.

81. Pelliccia A, Fagard R, Bjørnstad HH, Anastassakis A, Arbustini E, Corrado D, et al. Recommendations for competitive sports participation in athletes with cardiovascular disease A consensus document from the Study Group of Sports Cardiology of the Working Group of Cardiac Rehabilitation and Exercise Physiology and the Working Group of Myo. Eur Heart J. 2005;26:1422-45.

82. Heidbüchel H, Corrado D, Biffi A, Hoffmann E, Panhuyzen-Goedkoop N, Hoogsteen J, et al. Recommendations for participation in leisure-time physical activity and competitive sports of patients with arrhythmias and potentially arrhythmogenic conditions. Part II: ventricular arrhythmias, channelopathies and implantable defibrillators. Eur J Cardiovasc Prev Rehabil Off J Eur Soc Cardiol Work Groups Epidemiol Prev Card Rehabil Exerc Physiol. 2006;13(5):676-86.

83. Levine BD, Baggish AL, Kovacs RJ, Link MS, Maron MS Eligibility and disqualification recommendations for competitive athletes with cardiovascular of sports: dynamic, static, and impact. Am Coll Cardiol. 2015:2626.

84. Lampert R, Olshansky B, Heidbuchel H, Lawless C, Saarel E, Ackerman M, et al. Safety of sports for athletes with implantable cardioverter-defibrillators: long-term results of a prospective multinational registry. Circulation. 2017; 135:2310-2.

85. Zipes DP, Link MS, Ackerman MJ, Kovacs RJ, Myerburg RJ, Estes NAM 3rd. Eligibility and disqualification recommendations for competitive athletes with cardiovascular abnormalities: Task Force 9: arrhythmias and conduction defects: a scientific statement from the
American Heart Association and American College of Cardiology. Circulation. 2015;132(22):e315-25.

86. Olshansky B, Atteya G, Cannom D, Heidbuchel H, Saarel EV, Anfinsen O-G, et al. Competitive athletes with implantable cardioverter-defibrillators-how to program? Data from the implantable cardioverterdefibrillator sports registry. Heart Rhythm. 2019;16(4):581-7.

87. Lampert R. Sport participation in patients with implantable cardioverter-defibrillators. Curr Treat Options Cardiovasc Med. 2019;21(11):66.

88. Warburton DER, Nicol CW, Bredin SSD. Health benefits of physical activity: the evidence. C Can Med Assoc J $=\mathrm{J}$ l'Association medicale Can. 2006;174(6):801-9.

89. Dias KA, Link MS, Levine BD. Exercise training for patients with hypertrophic cardiomyopathy: JACC review topic of the week. J Am Coll Cardiol. 2018;72(10):1157-65.

90. Day SM. Exercise in hypertrophic cardiomyopathy. J Cardiovasc Transl Res. 2009;2(4):407-14.

91. Hindieh W, Adler A, Weissler-Snir A, Fourey D, Harris $\mathrm{S}$, Rakowski H. Exercise in patients with hypertrophic cardiomyopathy: a review of current evidence, national guideline recommendations and a proposal for a new direction to fitness. J Sci Med Sport. 2017;20(4):333-8.

92. Harmon KG, Asif IM, Maleszewski JJ, Owens DS, Prutkin JM, Salerno JC, et al. Incidence, cause, and comparative frequency of sudden cardiac death in $\mathrm{Na}$ tional Collegiate Athletic Association Athletes: a decade in review. Circulation. 2015;132(1):10-9.

93. Finocchiaro G, Papadakis M, Robertus J-L, Dhutia H, Steriotis AK, Tome M, et al. Etiology of sudden death in sports: insights from a United Kingdom regional registry. J Am Coll Cardiol. 2016;67(18):2108-15.

94. Aro AL, Nair SG, Reinier K, Jayaraman R, Stecker EC, Uy-Evanado A, et al. Population burden of sudden death associated with hypertrophic cardiomyopathy. Circulation. 2017;136:1665-7.

95. Bagnall RD, Weintraub RG, Ingles J, Duflou J, Yeates L, Lam L, et al. A prospective study of sudden cardiac death among children and young adults. N Engl J Med. 2016;374(25):2441-52.

96. Maron BJ, Haas TS, Ahluwalia A, Murphy CJ, Garberich RF. Demographics and epidemiology of sudden deaths in young competitive athletes: from the United States National Registry. Am J Med. 2016;129(11):1170-7.

97. Maron BJ, Udelson JE, Bonow RO, Nishimura RA, Ackerman MJ, Estes NAM 3rd, et al. Eligibility and disqualification recommendations for competitive athletes with cardiovascular abnormalities: Task Force 3: hypertrophic cardiomyopathy, arrhythmogenic right ventricular cardiomyopathy and other cardiomyopathies, and myocarditis: A Scientif. Circulation. 2015;132(22):e273-80 Available from: https://www. ncbi.nlm.nih.gov/pubmed/26621644.

98. Reineck E, Rolston B, Bragg-Gresham JL, Salberg L, Baty L, Kumar S, et al. Physical activity and other health behaviors in adults with hypertrophic cardiomyopathy. Am J Cardiol. 2013;111(7):1034-9. 
99. Sweeting J, Ingles J, Timperio A, Patterson J, Ball K, Semsarian C. Physical activity in hypertrophic cardiomyopathy: prevalence of inactivity and perceived barriers. Open Hear. 2016;3(2):e000484.

100. Luiten RC, Ormond K, Post L, Asif IM, Wheeler MT, Caleshu C. Exercise restrictions trigger psychological difficulty in active and athletic adults with hypertrophic cardiomyopathy. Open Hear. 2016;3(2):e000488

101. Konhilas JP, Watson PA, Maass A, Boucek DM, Horn $\mathrm{T}$, Stauffer BL, et al. Exercise can prevent and reverse the severity of hypertrophic cardiomyopathy. Circ Res. 2006;98(4):540-8.

102. Saberi S, Wheeler M, Bragg-Gresham J, Hornsby W, Agarwal PP, Attili A, et al. Effect of moderate-intensity exercise training on peak oxygen consumption in patients with hypertrophic cardiomyopathy: a randomized clinical trial. JAMA. 2017;317(13):1349-57.

103. Klempfner R, Kamerman T, Schwammenthal E, Nahshon A, Hay I, Goldenberg I, et al. Efficacy of exercise training in symptomatic patients with hypertrophic cardiomyopathy: results of a structured exercise training program in a cardiac rehabilitation center. Eur J Prev Cardiol. 2015;22(1):13-9.

104. Dejgaard LA, Haland TF, Lie OH, Ribe M, Bjune T, Leren IS, et al. Vigorous exercise in patients with hypertrophic cardiomyopathy. Int J Cardiol. 2018;250:157-63.

105. Howden EJ, Sarma S, Lawley JS, Opondo M, Cornwell $\mathrm{W}$, Stoller D, et al. Reversing the cardiac effects of sedentary aging in middle age-a randomized controlled trial: implications for heart failure prevention. Circulation. 2018;137(15):1549-60.

106. Pelliccia A, Lemme E, Maestrini V, Di Paolo FM, Pisicchio C, Di Gioia G, et al. Does sport participation worsen the clinical course of hypertrophic cardiomyopathy? Clinical outcome of hypertrophic cardiomyopathy in athletes. Circulation.

2018; 137:531-3

Describes outcomes of athletes with HCM who continued to participate in sporting activities despite recommendations to cease participation.

107. Pelliccia A, Caselli S, Pelliccia M, Musumeci MB, Lemme E, Di Paolo FM, et al. Clinical outcomes in adult athletes with hypertrophic cardiomyopathy: a 7-year follow-up study. Br J Sports Med. 2020;54(16):1008-12.

108. Spirito P, Autore C, Formisano F, Assenza GE, Biagini $\mathrm{E}$, Haas TS, et al. Risk of sudden death and outcome in patients with hypertrophic cardiomyopathy with benign presentation and without risk factors. Am J Cardiol. 2014;113(9):1550-5.

109. Ho CY, Olivotto I, Jacoby D, Lester SJ, Roe M, Wang A, et al. Study design and rationale of EXPLORER-HCM: evaluation of mavacamten in adults with symptomatic obstructive hypertrophic cardiomyopathy. Circ Heart Fail. 2020;13(6):e006853.

110. Olivotto I, Oreziak A, Barriales-Villa R, Abraham TP, Masri A, Garcia-Pavia P, et al. Mavacamten for treatment of symptomatic obstructive hypertrophic cardiomyopathy (EXPLORER-HCM): a randomised, double-blind, placebo-controlled, phase 3 trial. Lancet (London, England). 2020;396(10253):759-69.

\section{Publisher's Note}

Springer Nature remains neutral with regard to jurisdictional claims in published maps and institutional affiliations. 